\title{
Activity During the COVID-19 Pandemic
}

\author{
Jason T. Jakiela ${ }^{1}$ (D), Esther J. Waugh ${ }^{2}$, and Daniel K. White ${ }^{1}$ (D)
}

The emergence of the coronavirus disease 2019 (COVID-19) has resulted in unprecedented changes in how the world socially interacts. Limits on contact with others, whether by social distancing or shelter-at-home recommendations, have negatively affected physical activity (PA); this is especially true for adults over the age of 60 who are at high risk of serious illness from COVID-19. Adults with knee osteoarthritis (OA) is one particularly vulnerable group over the age of 60 . Knee OA alone affects over one-third of the general population over 60 years of age ${ }^{1}$ and is a leading cause of functional limitation (e.g., difficulty climbing stairs, getting up from a chair) ${ }^{2}$. There is no cure for $\mathrm{OA}$, but rather, treatment focuses on symptom management. Medical societies and clinical practice guidelines uniformly promote exercise as a first-line treatment approach for knee OA, with exercise shown to have greater improvements on pain and fewer adverse side effects when compared to nonsteroidal antiinflammatory drugs $s^{3}$. However, translating seemingly straightforward recommendations for exercise into practical messages remains problematic and a major problem during COVID-19, when physical activity is reduced. While previous work has reported that motivation for PA increases when adults with knee $\mathrm{OA}$ are provided a specific exercise prescription that factors in their condition, health professionals often struggle in making these specific exercise recommendations, resulting in a gap between treatment guidelines and actual practice.

Hence, we chose to make a minimal PA recommendation for adults with knee OA over 60 years. Our goal is to limit risk of inactivity-related poor health outcomes, such as lower body weakness and deconditioning by virtue of inactivity associated

${ }^{1} J . T$. Jakiela, $M S$, D.K. White, PT, ScD, MSc, University of Delaware, Department of Physical Therapy, Newark, Delaware, USA; ${ }^{2}$ E.J. Waugh, $B S c P T, M S c, P h D$, University of Toronto, Department of Physical Therapy, Toronto, Ontario, Canada.

Address correspondence to D.K. White, University of Delaware, Department of Physical Therapy, 540 South College Ave, 210L, Newark, DE 19713,

USA.Email:dkw@udel.edu. with COVID-19, in adults with knee OA. Hence, the purpose of this viewpoint is to suggest a succinct and clinically meaningful exercise recommendation for adults with knee $\mathrm{OA}$ in a time of limited social contact owing to COVID-19.

The first step is to recommend walking for at least 10 minutes each day We recommend health professionals consider encouraging adults with knee $\mathrm{OA}$ to walk for at least 10 minutes per day. We base this recommendation on the fact that adults use walking as a primary form of activity ${ }^{4}$. As well, walking is the most common type of leisure-time PA older adults employ and is simple, cost-effective, and accessible even in the home. Supporting this recommendation are the 2018 Physical Activity Guidelines for Americans ${ }^{5}$, which recommend that adults should move more and sit less throughout the day, and that any amount of moderate-to-vigorous intensity PA (MVPA) results in some health benefits. Walking can take place indoors on a treadmill or down a corridor if limited to the home, or outdoors while staying at least 6 feet apart from others.

Two studies in adults with, or at risk for, knee OA established benefits to physical function and disability through PA at lower duration thresholds than are set in the current PA guidelines. Dunlop and colleagues found that 45 minutes per week of MVPA is needed to improve low function or maintain high function, which equates to just over 6 minutes each day ${ }^{6}$. Dunlop's group also determined that 55-56 minutes per week of MVPA, or 8 minutes each day, best predicted being free from disability related to activities of daily living or mobility ${ }^{7}$. Further, walking for 10 continuous minutes per day at a moderate intensity is likely a safe and tolerable dosage for people with severe knee OA. In a small cohort of adults with advanced structural knee $\mathrm{OA}$, walking 70 minutes per week did not result in adverse knee pain during or after walking.

The second step is to recommend brisk walking

The current PA guidelines recommend at least moderate inten- 
sity exercise to increase general health benefits. OA-specific benefits, such as substantial reductions in risk of developing functional limitation, can be found at moderate intensities as well'. By walking at a brisk pace of at least 100 steps per minute, roughly equivalent to exercising at a moderate to vigorous intensity, it is possible to achieve these benefits ${ }^{10}$. Descriptively, brisk pace walking is characterized as building up a sweat, but still being able to carry on a conversation. The good news is that most adults with knee $\mathrm{OA}$ walk briskly (i.e., at least a moderate intensity) when at their usual pace ${ }^{11}$, and health benefits still exist for light activity for those unable to walk at a brisk pace ${ }^{12}$.

\section{Do not stop at 10 minutes}

We believe walking 10 minutes per day at a moderate intensity is an appropriate type and dosage of exercise to prescribe to most adults over 60 years because it provides an intensity and duration that affords important health benefits, and is a simple and attainable goal. While 10 minutes per day is an attainable starting point, it is important to encourage walking above this recommendation, given the dose-response health benefits of walking and PA in general. White and colleagues established a dose-response relationship between daily walking and protection against functional limitation ${ }^{13}$. Further, relative to inactive adults with knee OA, those who increased their PA levels saw improvements in their Late Life Disability Index score, with those meeting current PA recommendations seeing the greatest improvement ${ }^{14}$. As well, a dose-response relationship exists between PA and function in adults with knee OA, as those in the highest quartile of PA also had the fastest gait speed ${ }^{15}-$ a strong indicator of overall health. Methods to increase activity include walking for an additional 5 minutes each day for 1 week (Week 1: $10 \mathrm{~min}$, Week 2: $15 \mathrm{~min}$, Week 3: $20 \mathrm{~min}$, etc.) or using a pedometer to count steps working towards a goal of walking 6000 steps/day, which is a benchmark associated with protection from functional limitation ${ }^{13}$.

\section{Misconceptions and benefits of walking}

Despite these health benefits, approximately $40 \%$ of men and $57 \%$ of women with knee $\mathrm{OA}$ are considered inactive (i.e., performing zero bouts of MVPA during the week $)^{16}$. Misconceptions over walking resulting in joint damage and pain as an indicator of further harm are common, yet unsupported ${ }^{17}$. A previous review found no threats to safety in terms of increased pain, decreased function, structural progression, risk for total knee replacement, or increased adverse health events in older adults with knee pain who participated in long-term (up to 30 months) $\mathrm{PA}^{18}$. A metaanalysis from the Ottawa Panel concluded that aerobic walking programs were beneficial for adults over the age of 40 with mild to moderate knee $\mathrm{OA}^{19}$. The authors found the greatest improvements in pain, quality of life, and functional status, as well as a beneficial effect on stiffness, strength, mobility, and endurance ${ }^{19}$.

It is imperative to view exercise, and specifically walking, as an effective and "real" therapeutic option for adults with knee OA, especially during COVID-19. Recommending 10 minutes per day of walking is a simple and clear recommendation that is also beneficial. Studies have consistently demonstrated the bene- fits of an aerobic walking program to improve pain and function in patients with $\mathrm{OA}^{19}$. The evidence is clear: Aerobic walking provides clinically meaningful benefits for adults with knee OA.

\section{Conclusion}

We recommend health professionals provide a simple message to adults with knee OA to strive to walk at least 10 minutes per day, either indoors or outdoors, in the current COVID-19 climate. This recommendation is based on the current evidence, and accounts for tolerable pain limits (70 minutes per week) for those with OA, intensity equivalents (brisk walking at 100-130 steps per minute is moderate-to-vigorous intensity), and the dose-response benefits of PA. For adults with knee OA, walking for at least 10 minutes per day is important to mitigate inactivity-related impairments owing to limited contact with others during the COVID-19 pandemic.

\section{REFERENCES}

1. Lawrence RC, Felson DT, Helmick CG, Arnold LM, Choi H, Deyo RA, et al; National Arthritis Data Workgroup. Estimates of the prevalence of arthritis and other rheumatic conditions in the United States. Part II. Arthritis Rheum 2008;58:26-35.

2. Cross M, Smith E, Hoy D, Nolte S, Ackerman I, Fransen M, et al. The global burden of hip and knee osteoarthritis: estimates from the Global Burden of Disease 2010 study. Ann Rheum Dis 2014;73:1323-30.

3. McAlindon TE, Bannuru RR, Sullivan MC, Arden NK, Berenbaum F, Bierma-Zeinstra SM, et al. OARSI guidelines for the nonsurgical management of knee osteoarthritis. Osteoarthr Cartilage 2014;22:363-88.

4. Yusuf HR, Croft JB, Giles WH, Anda RF, Casper ML, Caspersen CJ, et al. Leisure-time physical activity among older adults. United States, 1990. Arch Intern Med 1996;156:1321-6.

5. U.S. Department of Health and Human Services. 2018 Physical Activity Guidelines Advisory Committee scientific report to the Secretary of Health and Human. [Internet. Accessed August 11, 2020.] Available from: health.gov/sites/default/files/2019-09/ PAG_Advisory_Committee_Report.pdf

6. Dunlop DD, Song J, Lee J, Gilbert AL, Semanik PA, Ehrlich-Jones $\mathrm{L}$, et al. Physical activity minimum threshold predicting improved function in adults with lower-extremity symptoms. Arthritis Care Res 2017;69:475-83.

7. Dunlop DD, Song J, Hootman JM, Nevitt MC, Semanik PA, Lee J, et al. One hour a week: moving to prevent disability in adults with lower extremity joint symptoms. Am J Prev Med 2019;56:664-72.

8. Wallis JA, Webster KE, Levinger P, Singh PJ, Fong C, Taylor NF. The maximum tolerated dose of walking for people with severe osteoarthritis of the knee: a phase I trial. Osteoarthritis Cartilage 2015;23:1285-93.

9. Fenton SA, Neogi T, Dunlop D, Nevitt M, Doherty M, Duda JL, et al; Multicenter Osteoarthritis Group. Does the intensity of daily walking matter for protecting against the development of a slow gait speed in people with or at high risk of knee osteoarthritis? An observational study. Osteoarthritis Cartilage 2018;26:1181-9.

10. Tudor-Locke C. Steps to better cardiovascular health: How many steps does it take to achieve good health and how confident are we in this number? Curr Cardiovasc Risk Rep 2010;4:271-6.

11. White DK, Tudor-Locke C, Felson DT, Gross KD, Niu J, Nevitt M, et al. Do radiographic disease and pain account for why people with or at high risk of knee osteoarthritis do not meet physical activity guidelines? Arthritis Rheum 2013;65:139-47. 
12. White DK, Lee J, Song J, Chang RW, Dunlop D. Potential functional benefit from light intensity physical activity in knee osteoarthritis. Am J Prev Med 2017;53:689-96.

13. White DK, Tudor-Locke C, Zhang Y, Fielding R, LaValley M, Felson DT, et al. Daily walking and the risk of incident functional limitation in knee osteoarthritis: an observational study. Arthritis Care Res 2014;66:1328-36

14. Song J, Gilbert AL, Chang RW, Pellegrini CA, Ehrlich-Jones LS, Lee J, et al. Do inactive older adults who increase physical activity experience less disability: evidence from the Osteoarthritis Initiative. J Clin Rheumatol 2017;23:26-32.

15. Dunlop DD, Song J, Semanik PA, Sharma L, Chang RW. Physical activity levels and functional performance in the osteoarthritis initiative: a graded relationship. Arthritis Rheum 2011;63:127-36.
16. Dunlop DD, Song J, Semanik PA, Chang RW, Sharma L, Bathon JM, et al. Objective physical activity measurement in the osteoarthritis initiative: are guidelines being met? Arthritis Rheum 2011;63:3372-82.

17. Bunzli S, O’Brien Bhealthsci P, Ayton D, Dowsey M, Gunn J, Choong P, et al. Misconceptions and the acceptance of evidence-based nonsurgical interventions for knee osteoarthritis. A qualitative study. Clin Orthop Relat Res 2019;477:1975-83.

18. Quicke JG, Foster NE, Thomas MJ, Holden MA. Is long-term physical activity safe for older adults with knee pain?: a systematic review. Osteoarthritis Cartilage 2015;23:1445-56.

19. Loew L, Brosseau L, Wells GA, Tugwell P, Kenny GP, Reid R, et al; Ottawa Panel. Ottawa panel evidence-based clinical practice guidelines for aerobic walking programs in the management of osteoarthritis. Arch Phys Med Rehabil 2012;93:1269-85. 